\title{
Programmable Bio-Nano-Chip System: A Flexible Diagnostic Platform that Learns
}

McDevitt JT'1,2,3*, McRae MP2, Simmons GW'1,2,3 and Christodoulides $\mathbf{N}^{2,3}$

${ }^{1}$ Department of Biomaterials, New York University College of Dentistry, New York, NY, USA

${ }^{2}$ Department of Bioengineering, Rice University, Houston, TX, USA

${ }^{3}$ Department of Chemistry, Rice University, Houston, TX, USA

Over the past few decades, the use of biomarkers has become increasingly intrinsic to the practice of medicine and clinical decisionmaking. Clinically validated biomarkers-whether nucleic acid, protein, or metabolite-provide health care providers and clinicians a means to quickly and objectively measure, track, and diagnose a patient's past and present physiological state for a wide range of conditions. As a result, biomarkers help patients receive appropriate care, which in turn helps reduce healthcare costs [1,2]. Biomarker-based tests are typically developed by diagnostic companies, and are often purchased and performed by medical testing companies. Biomarkers also aid pharmaceutical companies in quickly and efficiently screening their candidate drug products for dosing, pharmacokinetics, safety, and efficacy, thus simultaneously speeding up development and lowering the costs of drug. Upstream in the $\mathrm{R} \& \mathrm{D}$ continuum, early-stage researchers look for biomarkers to help better understand disease etiologies.

Because of the significant promise of biomarkers to improve healthcare, research in the field has risen rapidly in recent years. In 1990, there were about 200 published articles on biomarkers. By 2011, that number rose to well over 157,000 biomarker-related scientific publications [3]. Despite this huge amount of research, only about 1 protein biomarker per year is approved by the FDA; without such regulatory approval these biomarkers remain untapped potential [4]. This statistic is sobering, but it also illustrates tremendous opportunity for new technologies that will greatly enhance bench-to-bedside translation. Likewise, the completion of high-fidelity multiplexed and multiclass assays remains a huge task for the clinical, pharmaceutical, healthcare, insurance, microfluidics, biosensor, and medical microdevice communities as a whole, collectively emphasizing the critical need for a universal assay platform to provide the penultimate solution.

Today, there exist four major barriers to the full development and realization of such goals:

1) Integrating lab-on-a-chip (LOC) systems into point-of-care

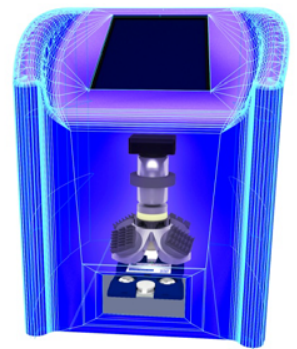

(a)

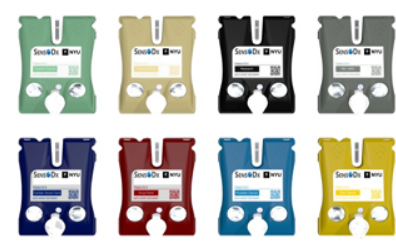

(b)
Figure 1: a) Programmable bio-nano-chip analyzer now in development alongside, b) Disease specific p-BNC cartridges that cover major health conditions.
(POC) structures that completely replicate the full functionality provided in remote laboratory settings;

2) Failure of current LOC systems to compete with remote testing, both from cost as well as performance perspectives;

3) LOC systems' need to develop new content that is unavailable at remote labs; and

4) Insights into multiple phases of regulatory approval that has traditionally taken decades to complete.

To help overcome these barriers, recently we have developed the Programmable Bio-Nano-Chip (p-BNC) system. This platform technology combines unique chem- and biosensing capabilities with powerful machine learning algorithms to provide novel and intuitive single-valued indices across several major diseases [5-12]. Nanomaterials and microelectronics have been combined and adapted for the practical implementation of two classes of mini-sensors (bead-based sensors for soluble chemistries and membrane-based chips for cytology) that read out with high-performance yet affordable imaging systems now in development, testing, and clinical validation. Collectively, the two p-BNC sensor ensembles form a modular platform system that demonstrates one of the largest analyte diversity available to date [6]. Microdevices with a demonstrated capacity to learn, the p-BNC system leverages machine learning algorithms and high dimensional data to identify otherwise undetectable patterns underlying various diseases. These rich data streams are managed with a novel database, and mobile health tools are integrated to help enroll patients, manage and collect their data, and provide precision feedback to healthcare providers and patients alike.

The advantages of high-throughput multiplex testing through high surface-to-volume ratios of solid support porous spheres have allowed for shorter analysis times consistent with the POC $[13,14]$ using low sample and reagent requirements. Further, the p-BNC assay characteristics now in development adhere to the guidelines for POC tests that have been developed and designated with the acronym COMMAND QUALS [9], that is Cheap, Obvious, Miniaturized, Multiplexed, Automated, Nonperishable, Dependable, Quick, Unobtrusive, Adaptable, Limited (volume), and Self-contained.

*Corresponding author: McDevitt JT, Department of Biomaterials, New York University College of Dentistry, New York, NY, USA, E-mail: mcdevitt@nyu.edu, 212-998-9204

Received April 28, 2015; Accepted April 30, 2015; Published May 10, 2015

Citation: McDevitt JT, McRae MP, Simmons GW, Christodoulides N (2015) Programmable Bio-Nano-Chip System: A Flexible Diagnostic Platform that Learns. J Biosens Bioelectron 6: e137. doi:10.4172/2155-6210.1000e137

Copyright: (C) $2015 \mathrm{McDevitt} \mathrm{JT}$, et al. This is an open-access article distributed under the terms of the Creative Commons Attribution License, which permits unrestricted use, distribution, and reproduction in any medium, provided the original author and source are credited. 
Citation: McDevitt JT, McRae MP, Simmons GW, Christodoulides N (2015) Programmable Bio-Nano-Chip System: A Flexible Diagnostic Platform that Learns. J Biosens Bioelectron 6: e137. doi:10.4172/2155-6210.1000e137

Page 2 of 2

\begin{tabular}{|c|c|c|c|c|c|}
\hline Study & Sponsor & Area & \# of subjects & Clinical Site & Bio-markers \\
\hline $\begin{array}{l}\text { Development of A Lab-on-a-Chip } \\
\text { System for Saliva-Based Diagnostics }\end{array}$ & $\begin{array}{l}\text { National Institute of Dental and } \\
\text { Craniofacial Research (NIDCR) }\end{array}$ & Cardiac Disease & 1,000 patients & $\begin{array}{l}\text { Baylor College of } \\
\text { Medicine }\end{array}$ & 15 proteins \\
\hline $\begin{array}{l}\text { Advanced Bio-Nano-Chips for } \\
\text { Saliva-Based Drug Tests at the Point } \\
\text { of Arrest }\end{array}$ & $\begin{array}{l}\text { Home Office-Center of Applied } \\
\text { Science and Technology (HO-CAST) }\end{array}$ & Drugs of Abuse & 240 participants & $\begin{array}{l}\text { Baylor College of } \\
\text { Medicine }\end{array}$ & 12 drugs \\
\hline \multirow{2}{*}{$\begin{array}{l}\text { Texas Cancer Diagnostics Pipeline } \\
\text { Consortium }\end{array}$} & $\begin{array}{l}\text { Cancer Prevention Research Institute } \\
\text { of Texas (CPRIT) }\end{array}$ & Ovarian Cancer & 1,250 patients & $\begin{array}{l}\text { MD Anderson Cancer } \\
\text { Center }\end{array}$ & 4 proteins \\
\hline & $\begin{array}{l}\text { Cancer Prevention Research Institute } \\
\text { of Texas (CPRIT) }\end{array}$ & Prostate Cancer & 400 patients & $\begin{array}{l}\text { UT Health Science } \\
\text { Center-San Antonio }\end{array}$ & 3 proteins \\
\hline $\begin{array}{l}\text { Pilot and Prospective Studies for the } \\
\text { Development of the Trauma Chip }\end{array}$ & Texas Emerging Technology Fund & Acute Kidney Failure & 120 patients & $\begin{array}{l}\text { UT Health Science } \\
\text { Center-Houston }\end{array}$ & 3 proteins \\
\hline $\begin{array}{l}\text { Development of p-BNCs for the } \\
\text { Monitoring of Anti-Epilepsy Drugs } \\
\text { Levels in Saliva }\end{array}$ & John S. Dunn Foundation & Epilepsy & 100 patients & $\begin{array}{l}\text { UT Health Science } \\
\text { Center-Houston }\end{array}$ & 3 proteins \\
\hline
\end{tabular}

Table 1: The bead-based p-BNC is involved in 6 clinical trials through several major sponsors to target a number of major diseases though the validation of a number of biomarkers.

In an attempt to move these medical microdevices into broadscale clinical practice, a number of clinical trials and pilot studies have been initiated. Likewise, the laboratory version (not shown here, but reported extensively previously) [5-10] along with the more recently developed integrated analyzer Figure $1 \mathrm{a}$ and p-BNC cartridges Figure $1 \mathrm{~b}$ are now involved in six clinical trials and two pilot studies, respectively, involving over 5,000 patients including over 10 clinical sites for diseases in the areas of cardiac heart disease, ovarian cancer, prostate cancer and drugs of abuse (Table 1).

In closing, high-impact diseases such as cardiovascular disease and various cancers (ovarian, oral, and prostate) are the targets of p-BNC development and significant biomarker validation trials. The ability to use validated biomarkers in a common platform affords interesting synergies with respect to opening up new and more efficient treatment methodologies for management of healthcare consumers and patients alike $[5,15]$. The same platform now is also dedicated to testing for antiepilepsy drugs, as well as drugs of abuse, with targeted applicability in various settings (e.g., home, dental screening, roadside drug testing). In many ways, the convergence of microfluidics, biomarker validation, and porous bead ensembles serve to overcome some of the significant challenges that the LOC communities have to date faced with respect to scalability and performance.

\section{References}

1. Rifai N, Gillette MA, Carr SA (2006) Protein biomarker discovery and validation: the long and uncertain path to clinical utility. Nature Biotechnol 24: 971-983.

2. Parikh NI, Vasan RS (2007) Assessing the clinical utility of biomarkers in medicine. Biomark Med 1: 419-436.

3. Roberts SA (2003) Drug metabolism and pharmacokinetics in drug discovery Current Opinion in Drug Discovery and Development 6: 66-80.

4. Anderson NL, Anderson NG (2002) The human plasma proteome: history, character, and diagnostic prospects. Mol Cell Proteomics 1: 845-867.

5. Jokerst JV, Jacobson JW, Bhagwandin BD, Floriano PN, Christodoulides N, et al. (2010) Programmable bano-nio-chip sensors: analytical meets clinical. Anal Chem 82: 1571-1579.

6. Chou J, Wong J, Christodoulides N, Floriano P, Sanchez X, et al. (2012) Porous bead-based diagnostic platforms: bridging the gaps in healthcare. Sensors 12 : 15467-15499.
7. Shadfan BH, Simmons AR, Simmons GW, Ho A, Wong J, et al. (2015) A multiplexable, microfluidic platform for the rapid quantitation of a biomarker panel for early ovarian cancer detection at the point-of-care. Cancer Prev Res 8: $37-48$.

8. Jokerst JV, Chou J, Camp JP, Wong J, Lennart A, et al. (2011) Location of biomarkers and reagents within agarose beads of a programmable bio-nanochip. Small 7: 613-624.

9. Jokerst JV, McDevitt JT (2010) Programmable nano-bio-chips: multifunctional clinical tools for use at the point-of-care. Nanomedicine 5: 143-155.

10. Weigum SE, Floriano PN, Christodoulides N, McDevitt JT (2007) Cell-based sensor for analysis of EGFR biomarker expression in oral cancer. Lab Chip 7 995-1003.

11. Christodoulides N, Mohanty S, Miller CS, Langub MC, Floriano PN, et al. (2005) Application of microchip assay system for the measurement of C-reactive protein in human saliva. Lab Chip 5: 261-269.

12. Christodoulides N, Pierre FN, Sanchez X, Li L, Hocquard K, et al. (2012) Programmable bio-nanochip technology for the diagnosis of cardiovascular disease at the point-of-care. Methodist Debakey Cardiovasc J 8: 6-12.

13. Peredy TR, Powers RD (1997) Bedside diagnostic testing of body fluids American Journal of Emergency Medicine 15: 400-407.

14. Altieri MF, Camarca M (2001) Point of care testing. Clin Pediatr Emerg Med 2: $275-79$

15. Floriano PN, Christodoulides N, Miller CS, Ebersole JL, Spertus J, et al. (2009) Use of saliva-based nano-biochip tests for acute myocardial infarction at the point of care: a feasibility study. Clin Chem 55: 1530-1538. 